\title{
Analisis Numerik Khamir dari Nektar Bunga Kebun Raya Baturraden dan Panggeran Hargobinangun
}

\section{Numerical Analysisof Flower Nectar Yeast from Baturraden Botanical Garden and Panggeran Hargobinangun}

\author{
Setiady CEB ${ }^{1}$, Ilmi $\mathbf{M}^{1}$ \\ ${ }^{1}$ Fakultas Biologi, Universitas Gadjah Mada, Jl. Teknika Selatan, Sekip Utara, Yogyakarta, 55281
}

Setiady CEB, Ilmi M. 2018 - Analisis Numerik Khamir dari Nektar Bunga Kebun Raya Baturraden dan Panggeran Hargobinangun 2 (2), 90-98.

\begin{abstract}
Abstrak
Khamir pada nektar bunga masih belum banyak diteliti di Indonesia. Padahal keragaman tanaman di Indonesia sangat tinggi karena letak geografis dan iklimnya. Oleh karena itu, penelitian ini bertujuan untuk mempelajari hubungan kekerabatan khamir pada nektar bunga melalui pendekatan taksonomi numerik. Metode yang dilakukan adalah mengisolasi khamir dari nektar bunga di Kebun Raya Baturraden dan Padukuhan Panggeran, Hargobinangun. Hasil isolasi kemudian dipurifikasi hingga menjadi isolat murni, kemudian diamati karakter morfologi, fisiologis, dan biokimia. Data dianalisis dengan koefisien Jaccard, dikelompokkan dengan metode UPGMA, dan disajikan dalam bentuk dendogram. Hasil analisis menunjukkan bahwa pada dendogram Jaccard'sCoefficient dengan menggunakan cut-off 70\%, didapatkan 3 klaster dan 1 outlier. Klaster I dan outlierIV yang berasal dari Padukuhan Panggeran diduga merupakan khamir Basidiomycetes, memiliki indeks kesamaan 63\%. Sementara klaster II dan III yang berasal dari Kebun Raya Baturraden, diduga merupakan khamir Ascomycetes dan memiliki indeks kesamaan 62\%.
\end{abstract}

Kata kunci - Kebun Raya Baturaden - khamir - nektar bunga - Panggeran - polinator

\begin{abstract}
A study on the flower nectar yeast in Indonesia has not been widely reported, Even though the diversity of plants in Indonesia is very high due to its geographical location and climate. Therefore, this study was aimed to determine the flower nectar yeast relationship through a numerical taxonomic method. Samples were collected from Baturraden Botanical Garden and Panggeran village. Isolation of yeast was conducted using BSEA (Bean SproutsExtract Agar). Data from morphological, physiological, and biochemical characterswas analyzed using UPGMA method with Jaccard coefficient. The result showed that 3 clusters and 1 outlier were determined in the dendogram using $70 \%$ cut-off Jaccard's Coefficient,. Cluster I and outlier IV from Panggeran village belong to basidiomycetous yeast with 63\% similarity. While clusters II and III from the Baturraden Botanical Gardens belong to ascomycetouss yeast with $62 \%$ similarity.
\end{abstract}

Key words - Baturraden Botanical Garden - flower nectar - Panggeran - pollinator - yeast

Dikirimkan27 Juni 2018, Diterima 14 November 2018, Terbit online 1 Desember 2018

Corresponding Author: Miftahul Ilmi - e-mail - m.ilmi@ugm.ac.id 


\section{Pendahuluan}

Indonesia memiliki keragaman tumbuhan yang tinggi karena letak geografis dan ilkimnya, dan 55\% tumbuhan berbunga di Indonesia merupakan tumbuhan endemik, menjadikan Indonesia sangat kaya akan keragaman tumbuhan berbunga. Nektar pada bunga, menjadi salah satu daya tarik bagi polinator untuk hinggap dan membantu penyerbukannya. Nektar merupakan senyawa dengan kandungan gula tinggi dan bersifat osmofil yang relevan dengan habitat hidup mikroorganisme seperti khamir. Nektar mengandung gula seperti sukrosa, glukosa, dan fruktosa, dengan konsentrasi yang berbeda tergantung pada jenis tumbuhan dan polinatornya (Chalcoff et al. 2006, Convention on Biological Diversity 2017).

Keberagaman khamir dalam nektar bunga dilaporkan cukup tinggi. Pozo et al. (2011) menemukan bahwa dari nektar bunga 24 jenis tumbuhan di bagian selatan Spanyol, khamir jenis Metschinikowiareukaufii dan M. gruessii paling mendominasi dari total 216 isolat yang didapatkan. Selain Metschinikowia, ditemukan juga khamir yang termasuk dalam marga Aureobasidium, Rhodotorula, Cryptococcus, Sporobolemyces, dan Lecythophora. de Vega et al. (2009) meneliti bahwa keragaman khamir pada nektar, berkorelasi dengan tipe polinator. Polinator berupa burung, teramati diversitas khamir pada bunga tinggi, sementara pada tanaman dan bunga dengan polinatorHymenoptera, diversitas khamir rendah. Penelitian yang dilakukan oleh Vega dan Herrera (2012) menunjukkan bahwa serangga baik semut maupun polinator memegang peran penting terhadap populasi khamir pada nektar bunga. Fokus penelitian di Indonesia yang berkaitan dengan keanekaragaman khamir, khususnya yang berhubungan dengan nektar dan polinator masih belum banyak dilakukan. Oleh sebab itu, perlu dilakukan penelitian untuk mengeksplorasi keanekaragaman khamir pada nektar bunga. Tujuan dari penelitian ini untuk mempelajari hubungan kekerabatan khamir pada nektar bunga melalui pendekatan taksonomi numerik fenetik.

\section{Metoda Penelitian}

\section{Isolasi dan purifikasi isolat}

Isolasi dilakukan dengan modifikasi metode dari Pozo et al. (2011). Nektar sampel bunga yang didapatkan dari Kebun Raya Baturraden dan Padukuhan Panggeran diinokulasikan kedalam medium Bean Sprouts Extract Agar(BSEA) pada cawan petri dengan metode swab, diinkubasi suhu $30^{\circ} \mathrm{C}$ selama 2-5 hari. Isolat yang tumbuh diseleksi dan dipurifikasi hingga menjadi isolat murni, kemudian disimpan di medium Malt Extract Agar (MEA).

\section{Karakterisasi morfologi dan fisiologi}

Pengujian karakter terhadap isolat khamir dilakukan dengan menggunakan panduan dari buku "The Yeast: A Taxonomic Study" oleh Kurtzman \& Fell (1998) dan Kurtzman et al. (2011). Karakter morfologi yang dikoleksi yaitu morfologi koloni meliputi warna, bentuk, permukaan, teksur, elevasi dan tepian koloni dan juga adanya pellicle; karakter morfologi sel meliputi bentuk, panjang dan lebar sel, perkembangbiakan aseksual, tipenya dan keberadaan pseudohifa. Pengujian karakter fisiologis yang dilakukan adalah fermentasi glukosa, galaktosa, sukrosa, maltosa dan laktosa, uji asimilasi sumber karbon dan nitrogen yaitu glukosa, galaktosa, sukrosa, laktosa, maltosa, manitol, asam sitrat, xilosa serta nitrit dan nitrat, pertumbuhan pada $1 \%$ asam asetat, produksi asam dari medium mengandung glukosa, pertumbuhan pada suhu $25^{\circ} \mathrm{C}, 30^{\circ} \mathrm{C}$ dan $37^{\circ} \mathrm{C}$, pertumbuhan pada $50 \%$ dan $60 \%$ glukosa, hidrolisis urea dan pencairan gelatin. 


\section{Analisis data}

Seluruh hasil pengamatan ditabulasikan dalam tabel $\mathrm{n} \times \mathrm{t}, \mathrm{n}$ untuk karakter yang diuji dan t untuk Operational Taxonomical Unit (OTU) yang digunakan. Hasil positif (+) bernilai 1, sementara hasil negatif (-) bernilai 0. Jika terdapat hasil ulangan yang berbeda, maka pengujian pada isolat tersebut diulang hingga hasil yang didapatkan seragam/ dominan. Data kemudian dianalisis menggunakan program Multi Variate Statistical Package (MVSP) berbasis Windows. Analisis hubungan kekerabatan didasarkan pada taksonomi numerik, yang menggunakan sifat-sifat pengujian fisiologis, biokimia dan sifat-sifat lainnya untuk mengklasifikasikan organisme (Sneath 2001). Similaritas tiap OTU dihitung dengan menggunakan Jaccard'sCoefficient (Priestand Austin, 1993):

$$
\text { JaccardCoefficient: } \frac{a}{a+b+c} \times 100 \%
$$

Keterangan:

$\mathrm{a}=$ jumlah karakter doublepositive pada kedua OTU yang diuji

$\mathrm{b}=$ jumlah karakter OTU pertama positif, sementara OTU kedua negatif

$\mathrm{c}=$ jumlah karakter OTU pertama negatif, OTU kedua positif

Analisis pengelompokan menggunakan Unweighted Pair Group Method with Arithmetic Average Mean (UPGMA). Hasil pengelompokan ini kemudian disajikan dalam dendogram.

\section{Hasil}

Isolasi khamir yang dilakukan menghasilkan total 20 isolat khamir dari kedua lokasi, dengan rincian 7 isolat dari sampel bunga Kebun Raya Baturraden dan 13 isolat dari Panggeran Hargobinagun (Tabel 1, Gambar 1).

Hasil clustering dari karakter yang telah diambil menunjukkan bahwa dengan cut-off sebesar 70\%, terdapat 3 klaster dan 1 outlier (Gambar 2). Klaster I beranggotakan seluruh isolat PG kecuali PG2.2, klaster II terdiri dari isolat BL6.4, BL8.21 dan BL8.22, anggota klaster III merupakan isolat BL6.1, BL6.22, BL7.1 dan BL7.2 dan 1 outlier yaitu isolat PG2.2.

Tabel 1 Kode sampel, jumlah dan kode isolat khamir dan marga sampel tanaman di Kebun Raya Baturraden dan Panggeran

\begin{tabular}{lllll}
\hline Lokasi Sampel & $\begin{array}{l}\text { Kode } \\
\text { sampel }\end{array}$ & $\begin{array}{l}\text { Jumlah } \\
\text { isolat }\end{array}$ & Kode isolat khamir & Marga sampel \\
\hline Kebun Raya & RA31 & 0 & - & - \\
Baturraden & RA32 & 0 & - & - \\
& RA33 & 0 & - & - \\
& RA34 & 0 & - & - \\
& RA35 & 0 & - & - \\
& RA36 & 0 & - & - \\
& RA37 & 0 & - & - \\
& RA38 & 0 & - & - \\
& BL1 & 0 & - & - \\
& BL2 & 0 & - & - \\
& BL3 & 0 & - & - \\
& BL4 & 0 & - & Hymenocallis
\end{tabular}




\begin{tabular}{lllll}
\hline Lokasi Sampel & $\begin{array}{l}\text { Kode } \\
\text { sampel }\end{array}$ & $\begin{array}{l}\text { Jumlah } \\
\text { isolat }\end{array}$ & Kode isolat khamir & Marga sampel \\
\hline BL7 & 2 & BL7.1, BL7.2 & Vanda \\
& BL8 & 2 & BL8.21, BL8.22 & Costus \\
& PL1 & 0 & - & - \\
PL2 & 0 & - & - \\
FB1 & 0 & - & - \\
& FB2 & 0 & - & - \\
FB3 & 0 & - & - \\
FB4 & 0 & - & - \\
FB5 & 0 & - & - \\
Panggeran (Asta & 0 & - & - \\
Bunda) & PG6 & 0 & - & - \\
& PG2 & 1 & PG1.1, PG1.2, PG1.3 & Petunia \\
& PG3 & 0 & - & Petunia \\
& PG4 & 1 & PG4.3 & - \\
PG5 & 2 & PG5.4, PG5.5 & Torenia \\
& PG6 & 0 & - & Saintpaulia \\
& PG7 & 0 & - & - \\
PG8 & 0 & - & - \\
PG9 & 0 & - & - \\
PG10 & 2 & PG10.11, PG10.12 & Capsicum \\
PG11 & 0 & - & - \\
PG12 & 4 & PG12.1, PG12.2, PG12.3, & Ochna \\
\hline
\end{tabular}
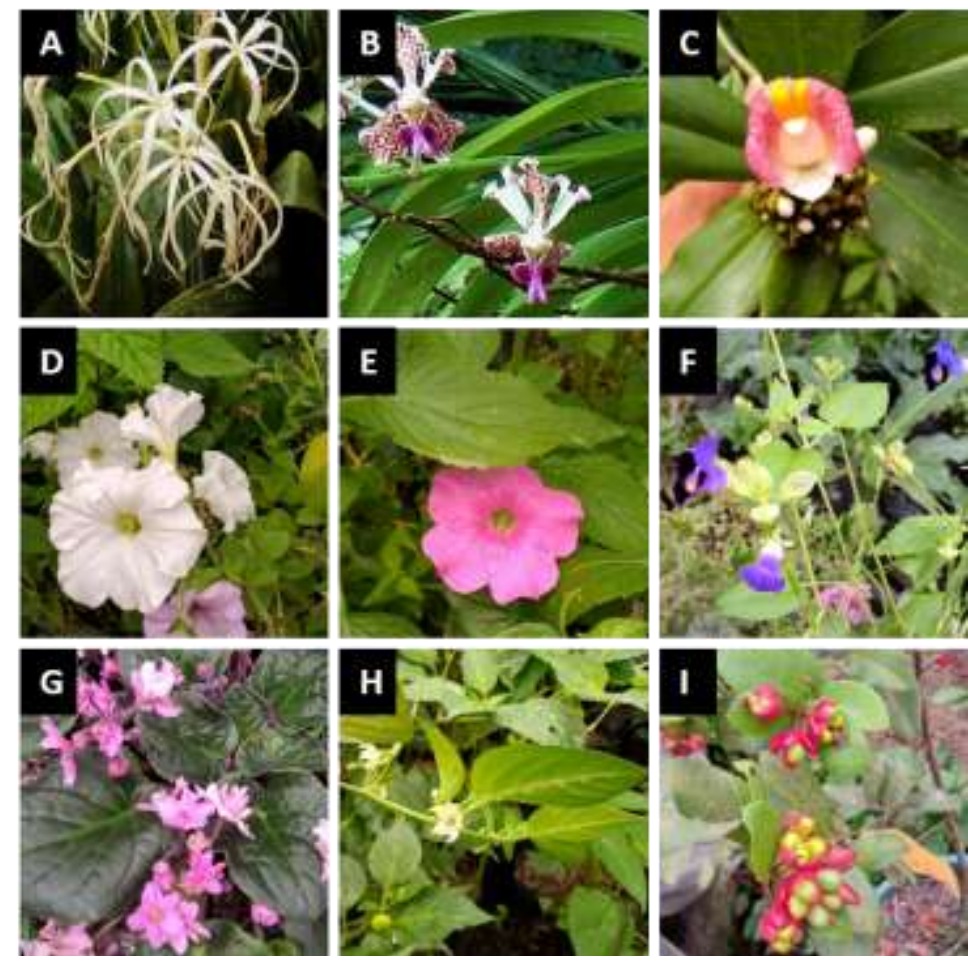

Gambar 1 Sampel Tanaman mengandung khamir. A.Hymenocallis sp.(BL6). B.Vanda sp. (BL7). C.Costus sp.(BL8). D.Petunia sp.(PG1). E.Petunia sp.(PG2). F.Torenia sp. (PG4). G.Saintpaulia sp.(PG5). H.Capsicum sp.(PG10). I.Ochna sp.(PG12) 


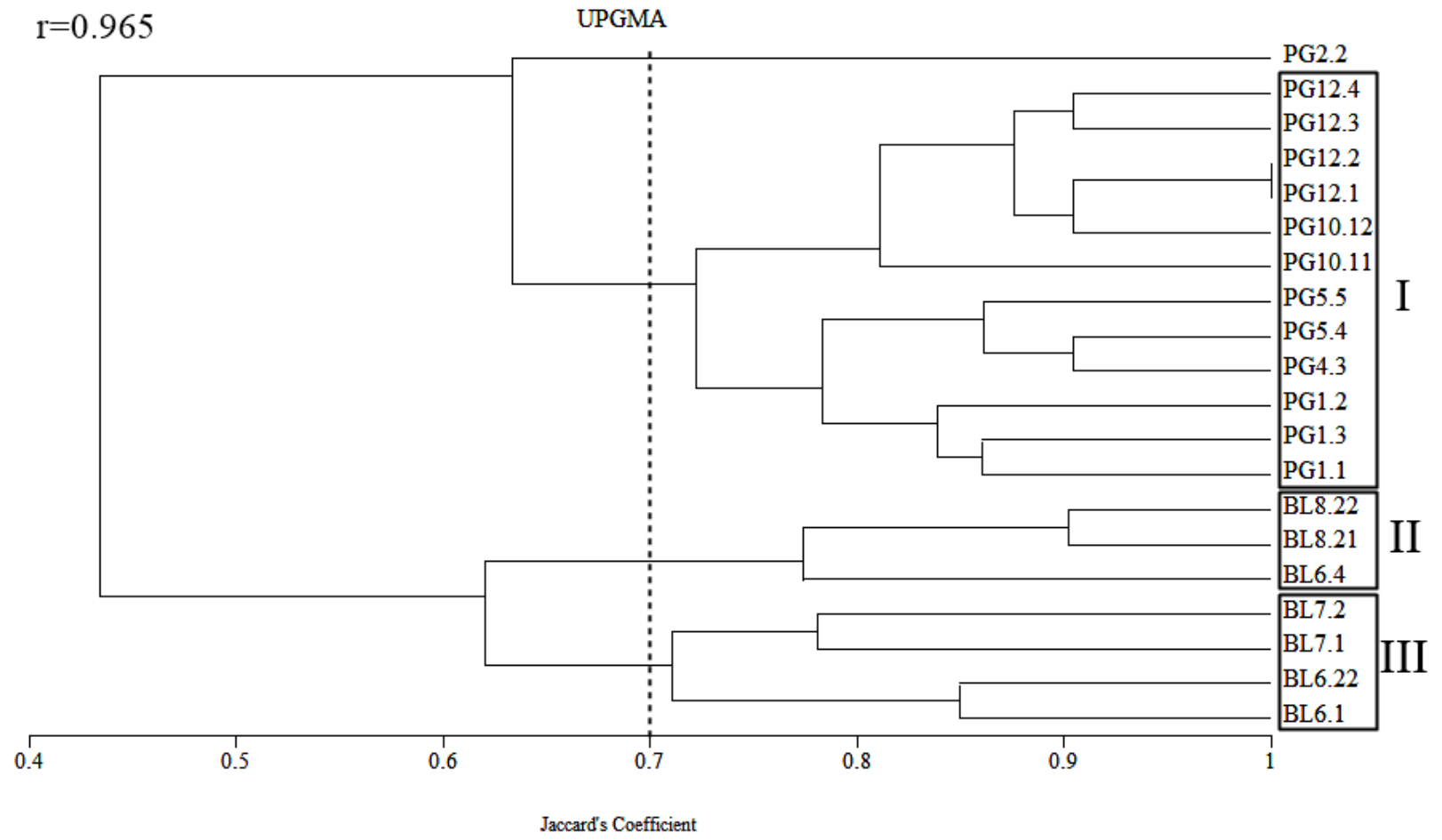

Gambar 2Dendogram analisis kluster 20 isolat khamir dari Kebun Raya Baturraden dan Panggeran, Hargobinangun dengan Jaccard'sCoefficient

Tabel 2 Persentase karakter positif yang dimiliki isolat pada masing-masing klaster khamir

\begin{tabular}{|c|c|c|c|c|c|c|}
\hline \multirow{2}{*}{ No } & \multirow{2}{*}{ Karakter } & \multirow{2}{*}{ Subkarakter } & \multicolumn{4}{|c|}{ Persentase isolat positif (\%) } \\
\hline & & & Klaster I & Klaster II & Klaster III & Outlier \\
\hline 1 & Bentuk Koloni & Circular & 100 & 100 & 100 & 100 \\
\hline 2 & Warna Koloni & White & 0 & 100 & 100 & 0 \\
\hline 3 & & Cream & 50 & 0 & 0 & 0 \\
\hline 4 & & Creamy Brown & 50 & 0 & 0 & 100 \\
\hline 5 & Permukaan Koloni & Dull & 75 & 67 & 25 & 0 \\
\hline 6 & & Glistening & 0 & 33 & 50 & 100 \\
\hline 7 & & Smooth & 25 & 0 & 25 & 0 \\
\hline 8 & & Wrinkled & 33 & 0 & 0 & 0 \\
\hline 9 & & Less Wrinkled & 67 & 0 & 0 & 0 \\
\hline 10 & Tekstur Koloni & Butyrous & 100 & 100 & 100 & 100 \\
\hline 11 & Elevasi Koloni & Raised & 100 & 0 & 25 & 100 \\
\hline 12 & & Convex & 0 & 100 & 75 & 0 \\
\hline 13 & Tepi Koloni & Entire & 67 & 100 & 100 & 100 \\
\hline 14 & & Entire with filament & 33 & 0 & 0 & 0 \\
\hline 15 & $\begin{array}{l}\text { Pertumbuhan pada } \\
\text { Medium Cair }\end{array}$ & Floating Pellicle & 100 & 100 & 0 & 100 \\
\hline 16 & Pellicle & Wrinkled & 83 & 0 & 0 & 0 \\
\hline 17 & & Dull & 17 & 0 & 0 & 100 \\
\hline 18 & & Glistening & 0 & 100 & 0 & 0 \\
\hline 19 & Bentuk Sel & Broadly Ellipsodial & 0 & 33 & 25 & 0 \\
\hline 20 & & Ellipsodial & 8 & 67 & 75 & 0 \\
\hline 21 & & Oval & 0 & 0 & 0 & 100 \\
\hline 22 & Bentuk Sel & Fusiform & 92 & 0 & 0 & 0 \\
\hline
\end{tabular}




\begin{tabular}{|c|c|c|c|c|c|c|}
\hline $\begin{array}{l}23 \\
24\end{array}$ & Rerata Panjang Sel & $\begin{array}{l}X,^{-}<4 \mu \mathrm{m} \\
4 \leq X^{-} \leq 6 \mu \mathrm{m}\end{array}$ & $\begin{array}{c}0 \\
17\end{array}$ & $\begin{array}{c}100 \\
0\end{array}$ & $\begin{array}{c}0 \\
100\end{array}$ & $\begin{array}{c}100 \\
0\end{array}$ \\
\hline No & & Subkarakter & \multicolumn{4}{|c|}{ Persentase isolat positif $(\%)$} \\
\hline & & & Klaster I & Klaster II & Klaster III & Outlier \\
\hline 25 & & $\mathrm{X},->6 \mu \mathrm{m}$ & 83 & 0 & 0 & 0 \\
\hline 26 & Rerata Lebar Sel & $\mathrm{X},-<2 \mu \mathrm{m}$ & 42 & 0 & 0 & 0 \\
\hline 27 & & $2 \leq \mathrm{X}^{-} \leq 3 \mu \mathrm{m}$ & 58 & 100 & 50 & 100 \\
\hline 28 & & $\mathrm{X}^{-}>3 \mu \mathrm{m}$ & 0 & 0 & 50 & 0 \\
\hline 29 & $\begin{array}{l}\text { Reproduksi } \\
\text { Aseksual }\end{array}$ & Budding & 100 & 100 & 100 & 100 \\
\hline 30 & Tipe Pertunasan & Unipolar & 0 & 67 & 0 & 0 \\
\hline 31 & & Polar & 100 & 0 & 0 & 100 \\
\hline 32 & & Multilateral & 0 & 33 & 100 & 0 \\
\hline 33 & Pseudohifa & Positive & 100 & 0 & 50 & 100 \\
\hline 34 & & Negative & 0 & 100 & 50 & 0 \\
\hline 35 & Asimilasi Sumber & Glucose & 100 & 100 & 100 & 100 \\
\hline 36 & Karbon dan & Galactose & 100 & 100 & 100 & 100 \\
\hline 37 & Nitrogen & Sucrose & 100 & 100 & 100 & 100 \\
\hline 38 & & Lactose & 100 & 100 & 100 & 100 \\
\hline 39 & & Maltose & 100 & 100 & 100 & 100 \\
\hline 40 & & Mannitol & 100 & 100 & 100 & 100 \\
\hline 41 & & CitricAcid & 100 & 100 & 100 & 100 \\
\hline 42 & & Xylose & 100 & 100 & 100 & 100 \\
\hline 43 & & Nitrate & 100 & 100 & 75 & 100 \\
\hline 44 & & Nitrite & 100 & 100 & 100 & 100 \\
\hline 45 & Fermentasi Glukosa & Strong Positive & 0 & 100 & 100 & 0 \\
\hline 46 & & Weak Positive & 50 & 0 & 0 & 100 \\
\hline 47 & & Non-Fermented & 50 & 0 & 0 & 0 \\
\hline 48 & $\begin{array}{l}\text { Fermentasi } \\
\text { Galaktosa }\end{array}$ & Weak Positive & 0 & 67 & 25 & 0 \\
\hline 49 & & Non-Fermented & 100 & 33 & 75 & 100 \\
\hline 50 & Fermentasi Sukrosa & Strong Positive & 0 & 100 & 0 & 0 \\
\hline 51 & & WeakPositive & 0 & 0 & 100 & 100 \\
\hline 52 & & Non-Fermented & 100 & 0 & 0 & 0 \\
\hline 53 & Fermentasi Laktosa & Non-Fermented & 100 & 100 & 100 & 100 \\
\hline 54 & Fermentasi Maltosa & StrongPositive & 0 & 100 & 100 & 0 \\
\hline 55 & & Non-Fermented & 100 & 0 & 0 & 100 \\
\hline 56 & $\begin{array}{l}\text { Pertumbuhan pada } \\
1 \% \text { Asam Asetat }\end{array}$ & Negative & 100 & 100 & 100 & 100 \\
\hline 57 & $\begin{array}{l}\text { Produksi asam dari } \\
\text { glukosa }\end{array}$ & Negative & 100 & 100 & 100 & 100 \\
\hline 58 & $\begin{array}{l}\text { Pertumbuhan pada } \\
\text { berbagai suhu }\end{array}$ & $25^{\circ} \mathrm{C}$ & 100 & 100 & 100 & 100 \\
\hline 59 & & $30^{\circ} \mathrm{C}(+)$ & 100 & 100 & 100 & 100 \\
\hline 60 & & $37^{\circ} C(+)$ & 100 & 0 & 25 & 100 \\
\hline 61 & & $37^{\circ} C(-)$ & 0 & 100 & 75 & 0 \\
\hline 62 & $\begin{array}{l}\text { Pertumbuhan pada } \\
50 \% \text { glukosa }\end{array}$ & Positive & 67 & 67 & 100 & 0 \\
\hline 63 & & Negative & 33 & 33 & 0 & 100 \\
\hline 64 & $\begin{array}{l}\text { Pertumbuhan pada } \\
60 \% \text { glukosa }\end{array}$ & Positive & 0 & 0 & 25 & 0 \\
\hline 65 & & Negative & 100 & 100 & 75 & 100 \\
\hline 66 & $\begin{array}{l}\text { Pertumbuhan pada } \\
10 \% \mathrm{NaCl}+5 \% \\
\text { glukosa }\end{array}$ & Positive & 17 & 0 & 75 & 100 \\
\hline 67 & & Slow Positive & 83 & 0 & 25 & 0 \\
\hline 68 & & Negative & 0 & 100 & 0 & 0 \\
\hline 69 & Hidrolisis Urea & Positive & 100 & 0 & 0 & 100 \\
\hline 70 & & Negative & 0 & 100 & 100 & 0 \\
\hline
\end{tabular}




\begin{tabular}{|c|c|c|c|c|c|c|}
\hline 71 & Pencairan Gelatin & Positive & 100 & 67 & 100 & 100 \\
\hline 72 & & Negative & 0 & 33 & 0 & 0 \\
\hline
\end{tabular}

\section{Pembahasan}

Berdasarkan tahapan isolasi yang telah dilakukan, dari 25 sampel bunga yang diambil di Kebun Raya Baturraden, Jawa Tengah, populasi khamir hanya ditemukan pada 3 sampel bunga (12\%). Sementara dari 12 sampel bunga PadukuhanPanggeran, Hargobinangun, D.I. Yogyakarta yang dikoleksi dan diisolasi, populasi khamir didapati pada 6 sampel bunga (50\%) (Tabel 1). Rendahnya populasi khamir pada sampel Kebun Raya Baturraden (selanjutnya disebut KRB), dimungkinkan karena sehari sebelum pengambilan sampel nektar turun hujan. Turunnya hujan dimungkinkan menghilangkan populasi mikrobia nektar, sehingga isolat khamir yang didapatkan sedikit.

Hasil analisis dengan Jaccard's Coefficient, menggunakan cut-off pada indeks kesamaan (similarity) 70\%, didapatkan 3 klaster dan 1 outlier berupa isolat tunggal, PG2.2 (Gambar 2). Penggunaan cut-off pada indeks kesamaan $70 \%$ didasarkan pada penelitian Campbell (1972) yang menyatakan bahwa isolat yang memiliki indeks kesamaan lebih dari $70 \%$ termasuk kedalam satu marga yang sama. Sehingga dari hasil analisis yang telah dilakukan, diduga terdapat 4 marga khamir yang berbeda.

Berikut adalah karakteristik kunci yang membedakan tiap marga dengan marga lainnya.

1. Klaster/marga I (PG1.1, PG1.2, PG1.3, PG4.3, PG5.4, PG5.5, PG10.11, PG10.12, PG12.1, PG12.2, PG12.3 dan PG12.4) memiliki koloni raised, perkembangbiakkan aseksual dengan polar budding, memiliki pseudohifa, umumnya memiliki bentuk sel fusiform, dapat mengasimilasi nitrat, tidak mampu memfermentasi galaktosa, maltosa, dan sukrosa, mampu tumbuh pada suhu $37^{\circ} \mathrm{C}$, mampu tumbuh pada $10 \% \mathrm{NaCl}$ dan $5 \%$ glukosa, tidak mampu tumbuh pada glukosa 60\%, mampu menghidrolisis urea, dan mampu melarutkan gelatin.

2. Klaster/marga II (BL6.4, BL8.21 dan BL8.22) memiliki koloni berwarna putih, convex, tepian entire, membentuk floating glistening pellicle, panjang sel kurang dari $4 \mu \mathrm{m}$, lebar sel antara 2-3 $\mu \mathrm{m}$, bertunas, tidak memiliki pseudohifa, mampu mengasimilasi nitrat, mampu memfermentasi glukosa, sukrosa dan maltosa, tidak mampu tumbuh pada suhu $37^{\circ} \mathrm{C}$, tidak mampu tumbuh pada glukosa $60 \%$, dan tidak mampu menghidrolisis urea.

3. Klaster/marga III (BL6.1, BL6.22, BL7.1 dan BL7.2) memiliki karakter berupa warna koloni putih, butyrous, entire, panjang sel 4-6 $\mu \mathrm{m}$, perkembangbiakan aseksual dengan pertunasan multilateral, mampu memfermentasi glukosa, maltosa dan sukrosa (lemah), mampu tumbuh pada suhu $37^{\circ} \mathrm{C}$, mampu tumbuh pada glukosa $50 \%$, tidak mampu menghidrolisis urea, dan mampu melarutkan gelatin.

4. Outlier IV (PG2.2) memiliki koloni raised, perkembangbiakan aseksual dengan polar budding, memiliki pseudohifa, memiliki bentuk sel oval, dapat mengasimilasi nitrat, mampu memfermentasi glukosa (lemah), maltosa (lemah), dan sukrosa (lemah), mampu tumbuh pada suhu $37^{\circ} \mathrm{C}$, mampu tumbuh pada $10 \% \mathrm{NaCl}$ dan $5 \%$ glukosa, tidak mampu tumbuh pada glukosa $50 \%$ dan $60 \%$, mampu menghidrolisis urea, dan mampu melarutkan gelatin.

Berdasarkan uji karakter yang telah dilakukan terhadap seluruh isolat, beberapa karakter bernilai sama untuk semua isolat, seperti hasil negatif pada uji fermentasi laktosa, pertumbuhan pada $1 \%$ asam asetat, dan produksi asam dari glukosa (Tabel 2). Seluruh isolat memiliki kenampakan koloni butyrous, atau menyerupai mentega. Seluruh isolat juga mampu mengasimilasi glukosa, galaktosa, maltosa, sukrosa, laktosa, asam sitrat, xilosa, manitol dan nitrit. 
Klaster/marga I diduga merupakan khamir Basidiomycetes, karakteristik utama adalah tidak memiliki kemampuan fermentasi, yang membedakan dengan outlier IV. Klaster ini dibedakan dengan klaster II dan III pada karakter pseudohifa, dimana seluruh isolat pada klaster I memiliki pseudohifa. Isolat ini juga mampu melarutkan gelatin yang menunjukkan kemampuan proteolitik.

Klater/marga II diduga merupakan khamir Ascomycetes dilihat dari karakter uji hidrolisis urea yang bernilai negatif. Isolat ini merupakan isolat fermentatif yang baik, terlihat dari kemampuannya memfermentasi gluksoa, maltosa dan sukrosa. Diduga hasil fermentasi yang dihasilkan adalah alkohol, mengingat tidak adanya isolat yang mampu memproduksi asam dari glukosa.

Klaster/marga III diduga merupakan khamir Ascomycetes, dan yang membedakannya dengan kluster II adalah klaster ini hanya menghasilkan hasil weak positive pada fermentasi sukrosa. Perbedaan lain adalah kemampuan dalam melarutkan gelatin yang menunjukkan aktifitas proteolitik pada seluruh isolat klaster III. Klaster ini memiliki ukuran sel yang cenderung lebih besar jika dibandingkan dengan klaster II. Klaster ini memiliki kesamaan dengan klaster II dimana tidak adanya pseudohifa yang terbentuk dan memiliki bentuk koloni yang mirip.

Penelitian Pozo et al. (2009) menyatakan bahwa dimungkinkan khamir, yang banyak menjadikan nektar bunga tanaman Angiosperm sebagai habitatnya, memiliki peranan untuk menjadi agen perantara persinyalan antara tanaman dengan polinator melalui aroma hasil fermentasi gula yang khas. Aroma yang dihasilkan dari fermentasi diduga menarik polinator untuk hinggap dan menyerbukinya atau membawa polen ke bunga yang lain. Penelitian ini diperkuat oleh penelitian yang dilakukan oleh Good et al. (2014), yang menyatakan bahwa keberadaan mikrobia berupa bakteri di dalam nektar mempengaruhi preferensi lebah madu (Apismellifera). A. mellifera cenderung menghindari nektar mengandung bakteri, namun tidak pada nektar mengandung khamir. Diduga bahwa bukan keberadaan bakteri yang membuat A. mellifera menghindari nektar, namun karena senyawa kimia yang ada pada nektar akibat aktifitas bakteri. Hipotesa ini mendukung hasil yang didapatkan. Pada kedua lokasi sampel, ada kemiripan antar isolat yang ditemukan di masing-masing lokasi, dimanasimiliaritas antara klaster II dan III yang berasal dari Kebun Raya Baturraden adalah $62 \%$. Sedangkan tingkat similiaritas pada klaster I dan outlier IV yang berasal dari Panggeran adalah 63\%, mengindikasikan bahwa kekerabatan antar spesies dalam satu lokasi cukup dekat.

Berdasarkan hasil yang didapatkan dapat disimpulkan bahwa khamir yang berasal dari Kebun Raya Baturraden memiliki karakteristik kunci yaitu warna koloni putih, memiliki aktifitas fermentasi serta tidak mampu menghidrolisis urea. Khamir yang berasal dari Padukuhan Panggeran memiliki karakteristik kunci yaitu koloni yang berwarna jingga kecoklatan, tidak/ rendahnya aktifitas fermentasi serta teramatinya aktifitas hidrolisis urea. Klasifikasi numerik fenetik dengan Jaccard'sCoefficient dan cut-off pada indeks kesamaan 70\% menghasilkan 3 klaster yaitu klaster I, klaster II dan klaster III serta 1 outlier. Klaster I dan outlier diduga merupakan khamir Basidiomycota, sedangkan klaster II klaster III diduga khamir Ascomycota.

\section{Ucapan Terima Kasih}

Terima kasih kami sampaikan kepada Kepala Kebun Raya Baturraden, Purwokerto, serta pemilik pembibitan bunga di Padukuhan Panggeran Hargobinangun, D.I. Yogyakarta, yang telah memberikan izin untuk pengambilan sampel.

\section{Pustaka}


Campbell I. 1972 - Numerical analysis of the genera Saccharomyces and Kluyveromyces. J Gen Microbiol 73, 279-301.

Chalcoff VR, Aizen MA, Galetto L. 2006 - Nectar concentration and composition of 26 species from the temperate forest of South America. Ann Bot 97, 413-21.

Conventionon Biological Diversity. 2017 - Indonesia - country profile. [accessed 2018 Jan 10]. https://www.cbd.int/countries/profile/default.shtml?country=id\#facts.

Good AP, Gauthier ML, Vannette RL, Fukami T. 2014 - Honey bees avoid nectar colonized by three bacterial species, but not by a yeast species, isolated from the bee gut. PLOS One 9(1), e86494.

Kurtzman CP, Fell JW. 1998 - The yeasts, ataxonomic study. 4th ed. Amsterdam: Elsevier Science.

Kurtzman CP, Fell JW, Boekhout T. 2011 - The yeasts: ataxonomic study. 5th ed. London: Elsevier Science.

Pozo MI, Herrera CM, Bazaga P. 2011 - Species richness of yeast communities in floral nectar of southern Spanish plants. MicrobEcol 61, 82-91.

Pozo MI, Vega C De, Canto A, Herrera CM. 2009 - Presence of yeasts in floral nectar is consistent with the hypothesis of microbial-mediated signaling in plant-pollinator interactions. Plant Signal Behav 4, 1102-1104.

Vega C De, Herrera CM. 2012 - Relationships among nectar-dwelling yeasts, flowers and ants: patterns and incidence on nectar traits. Oikos 121, 1-11.

de Vega C, Herrera CM, Johnson SD. 2009 - Yeasts in floral nectar of some South African plants: quantification and associations with pollinator type and sugar concentration. South African J Bot 75, 798-806. 